\title{
CELLULAR AUTOMATA MODEL - LANDSCAPE DYNAMICS SIMULATION TOOL IN THE PROCESS OF CHANGE IN LAND USE AND COVER IN THE CITY OF GAÚCHA DO NORTE - MT
}

\author{
E. A. L. Pinheiro ${ }^{1}$, N. A. Camini ${ }^{1}$, M. R. S. Soares ${ }^{1}$, S. S. Sumida ${ }^{1}$ \\ ${ }^{1}$ Graduate Program in Analysis and Modeling of Environmental Systems, Institute of Geosciences - IGC / UFMG, Av. \\ Antonio Carlos, 6627, Pampulha - Belo Horizonte - MG - CEP 31270-901, Brazil.
}

KEY WORDS: LUCC, Cellular Automata Model, Protected Areas, Simulation, Scenarios.

\begin{abstract}
:
The factors that contribute to land use change in the municipality of Gaúcha do Norte - MT, are entirely linked to the economic process and agricultural production. This process has left brazil in a state of alert due to the process of deforestation and loss of tropical forests. From 2000 to 2010, the forest areas converted into agriculture accounted for $13.3 \%$, the main factor that directly potentiated with deforestation was the cultivation of soybeans, which in turn was occupying places previously occupied by livestock and pushing the livestock forest inside. The phenomena of land use change and land cover start from multidimensional issues in the environmental and economic context. The use of environmental modeling through cellular automata to analyze land use change phenomena and reproduce the trajectory through future land use simulations and evolution establishes an integration associated by mathematical models and flow integration systems. That predict the trajectory of land use change, thus generating a dynamic model capable of predicting future land use changes by replicating possible patterns of landscape evolution and enabling assessments of future ecological implications for the environment.
\end{abstract}

\section{INTRODUCTION}

Great economic demand for agricultural production, has left Brazil on alert mainly in the main agricultural frontier of the country: The Amazon and Cerrado. In the context of the processes of loss of tropical forests, Brazil is the country that most deforested its vegetation cover, according to the United Nations Food and Agriculture Organization (Fao). Despite efforts by the country to reduce the destruction of the Amazon rainforest, for example, in the 21 st century, there was an average loss of 17,600 $\mathrm{km}^{2}$ of natural forests belonging to this biome.

The disputes of interest between small and large producers in the agricultural sector, has raised the environmental and climate change debates of the largest tropical forest in the world, putting in check the importance of biodiversity of fauna and flora and water resources in the Brazilian context. Given these threat perspectives, impacts on the Amazon rainforest are grounded in changes in land cover driven by historical processes, which are due to both urban sprawl, agricultural production, and energy. (Cassman, 1999; Tilman d. 2002), points out that global production of grains, meat, energy and other agricultural products has doubled in recent decades, the globalization process of rising incomes overestimated new demands that boosted intensive agriculture, availability of new arable land.

In this controversial scenario to sustainable and conscious development, in 2009, in the state of Mato Grosso $19 \%$ of the Amazonian biome located in the state, were converted into areas of agricultural expansion. In the region of the municipality of Gaúcha do Norte - MT, from 2000 to 2010 the forest areas converted into agriculture represented $13.3 \%$, the main factor that directly potentiated with deforestation was the cultivation of soybeans, which in turn was occupying places that until then were occupied by livestock and pushing the forest livestock in.

Thus, the objective of this paper is to analyze the anthropogenic effects and the main factors that contribute to land use change in the municipality of Gaúcha do Norte - MT, as well as to simulate the dynamics of land use and land cover for future scenarios based on current configurations.

\section{THEORETICAL FOUNDATION}

The Amazon rainforest is the largest rainforest in the world, the deforestation process has long been associated with extensive livestock, nowadays the reality is associated with the shift from the rainforest to soybean and corn agriculture. Grain production in the Amazon rainforest region has become the second largest exporter in the world, largely in the state of Mato Grosso (Morton, 2006; Fao, 2012; Macedo et. al., 2012).

The phenomena of land use change and land cover essentially derive from developmental methods and multidimensional environmental and economic issues. The idea of using environmental modeling to analyze phenomena in land use change is a means of understanding current relationships and inferring future changes, capable of reproducing future trajectory and evolution (Allen, 1997; Batty, 1996; Batty et al., 1999).

In order to represent the dynamics of environmental systems and their interactions through simulations, land use models establish robust diagnostics, prediction and simulation through mathematical models, logical systems and flow interactions between various spatial elements, which predict possibilities of land use change trajectory, generating a dynamic model.

(Soares-Filho et al., 2002), highlights that dynamic models predict future changes in land use and replicate possible patterns of landscape evolution, enabling assessments of future ecological implications in the environment.

The conversion of areas outside the Xingu protected areas has been massive and intense, leading to an increase from $25 \%$ in 2001 to over $40 \%$ in 2010, following this scenario with deforestation clearance data from the State Secretariat of Environment of the State of Mato Grosso, which shows that in $2018,85 \%$ of areas were deforested without authorization of deforestation or vegetation suppression (Macedo et al, 2012). The process of land use transitions from forests to intensively 
managed agricultural landscapes has several potential consequences for social and environmental systems in the Amazon (Brando et al, 2013).

\section{STUDY AREA}

Located in the geographical region of Rondonópolis, the municipality of Gaúcha do Norte in the state of Mato Grosso has an economy based mainly on agriculture, occupying $328,568,534$ ha $(19.45 \%)$ of its area distributed between crops and pasture. Taking into account that the region of the municipality presents two major Brazilian biomes: Amazon and Cerrado, which corresponds to $65 \%$ and $35 \%$ respectively in relation to the area of the municipality, besides the Xingu Indigenous Park that occupies about $50 \%$ of its territory in the northern portion, which concentrates the entire economy of the municipality to the south (Figure 1).

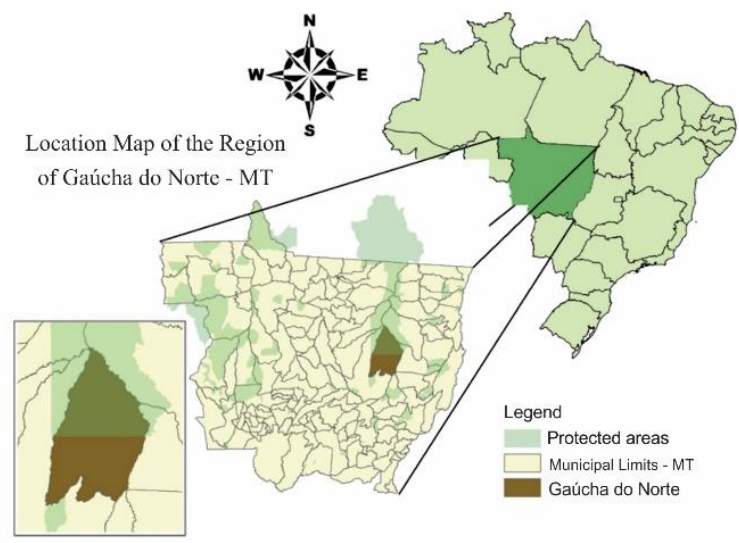

Figure 1: Municipality of Gaúcha do Norte - highlighting the Xingu Indigenous Land.

\section{METHODOLOGY}

The methodological procedures for analysis of LUCC - Land Use Cover Change processes of the present study, started from the use of Dinamica-EGO - Environment for Geoprocessing Objects software. The development of environmental modeling of the construction of a spatially explicit model focused on the analysis and simulation of spatiotemporal phenomena of land use change, by means of cellular automata (CA) modeling of transition cells.

The modeling of land use change on the platform was done through 3 steps:

1 - Acquisition of MapBioma images (2000, 2010 and 2016) and reclassification and 3 classes: Forests, Agriculture and Other Uses.

2 - Cartographic survey of variables that justify land use change or not, categorization and weights of evidence, analysis of correlations of variables and calibration of the land use change model.

3 - The process of validation and creation of landscape maps, probability, null model was performed to analyze the change of land use at random, without the insertion of variables, thus verifying how explanatory the model is with the variables, in Then, future scenarios were simulated (Figure 2).

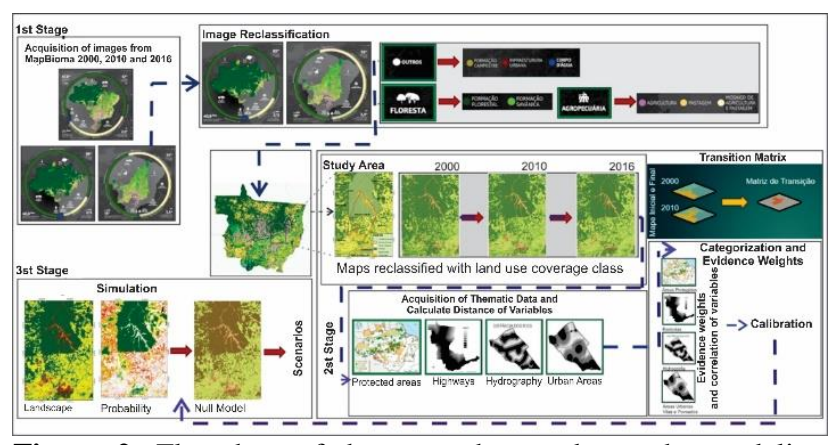

Figure 2: Flowchart of the steps that made up the modeling process, using the Dinamica-EGO software.

MapBioma images were acquired from 2000 to 2016, the image classification process was performed by the Dynamic SoftwareEGO, with the Calculate Maper tool, then a survey of variables capable of explaining the soil change process was performed. In the region, the variables selected were the distances from protected areas (protected areas and indigenous lands, hydrographic distances, distances from urban areas, settlements and federal, state and vicinal highways (Nepstad et al., 2000; Soares-Filho et al., 2005).

The model calibration process used images from the year 2000 and 2010, and is based on the categorization of variables, weighting of evidence and correlation of variables so that variables that have a high correlation with each other can discarded so as not to prejudice the analysis of the results (Bonham-Carter, 1994). This method was adapted from the (Agterberg and Bonham Carter, 1990) methodology, where the model analyzes the occurrence of change and quantifies by means of evidence weights to the land use change transition within the distances of the variables (Agterberg and Bonham-Carter, Goodacre et al 1993; Bonham-Carter 1994).

\section{RESULTS}

From the images acquired from the Map Biomes from 2000 to 2010, the images were reclassified, composing the Forest Formation, Farming and Other Uses classes. Figure 3, shows the change in the structure of the region, in the period of 10 years.

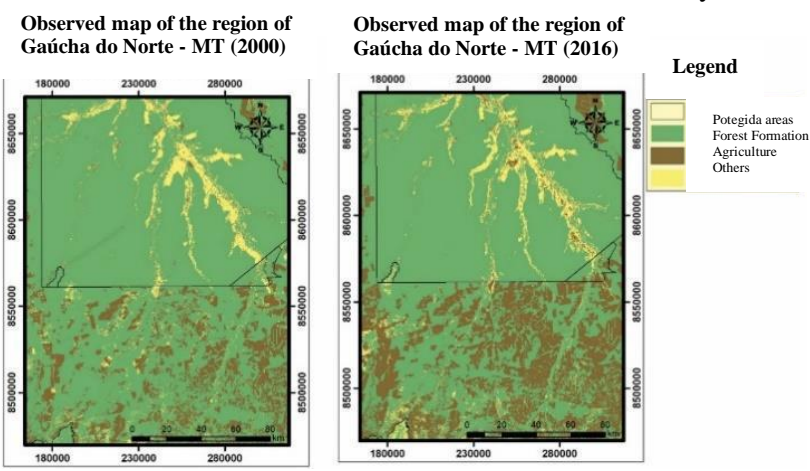

Figure 3: Observation maps of the land use transition from 2000 to 2010 for the study área

There is, therefore, a clear movement of consolidation of the large rural property, which shows the transition of natural areas towards their occupation for the purposes of agricultural production (Graph 1). 


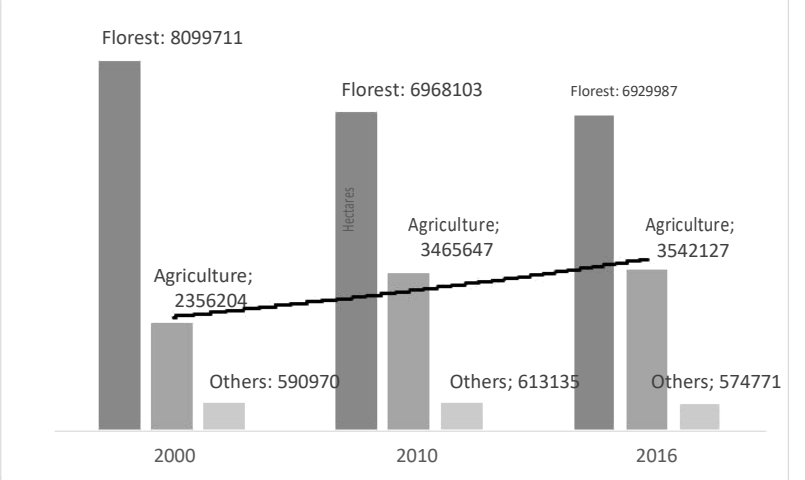

Graph 1: Configuration of land use change in the region of the municipality of Gaúcha do Norte - MT, highlighting the expansion of areas for agricultural purposes, between 2000, 2010 and 2016 .

Although the municipality of Gaúcha do Norte is relatively new, this land use and occupation trend reflects the expansion process that took place in the history of the occupation of the state of Mato Grosso itself. Since the 1950s, when the Mato Grosso State Government through the colonization project has benefited land ownership for many people for economic integration, many of them have been used for business speculation, especially with migration from the states of the state. Southern Brazil. To execute the project of "integration" of the Amazon these spaces were cut by highways, triggering a violent and rapid process of expropriation and domination.

Thus, the State of Mato Grosso followed the dynamics of agricultural production in the Brazilian Cerrado, centered on large property, directed to the production of grain for export, especially from the 1980s. This trend has expanded the agricultural frontier towards the Central In the West, due to several factors, such as technological advances, which made it possible, together with the region's edaphoclimatic characteristics, to achieve a very high physical productivity per area, improvements in transport infrastructure and distribution and outbound logistics. production. Despite the investment in logistics and infrastructure issues, however, it is noteworthy that the modeling process of the study area has shown that, however large the influence of factors such as highways, roads, urban densities, the process of substitution of Forested areas by productive units (Charts) were mainly due to a movement proper to the expansion of the land domain over the territory. Thus showing the expansion of land tenure by its market value and as a market reserve, with its possible later occupation by agricultural activities.

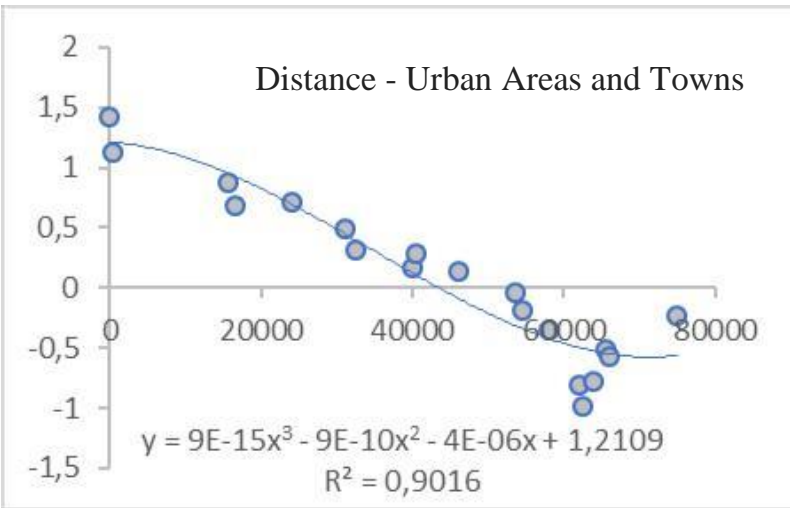

Graph 2: Linear relationship between land use change and distances from urban and populated areas.

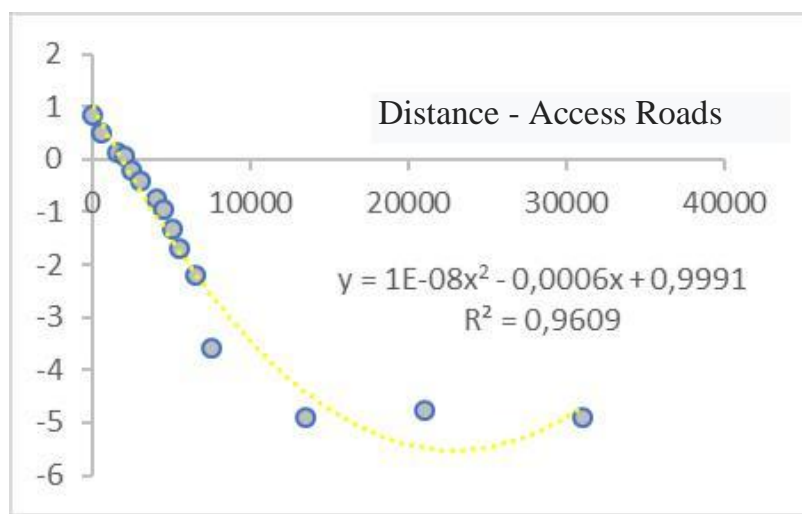

Graph 3: Linear relationship between land use change and access road distances.

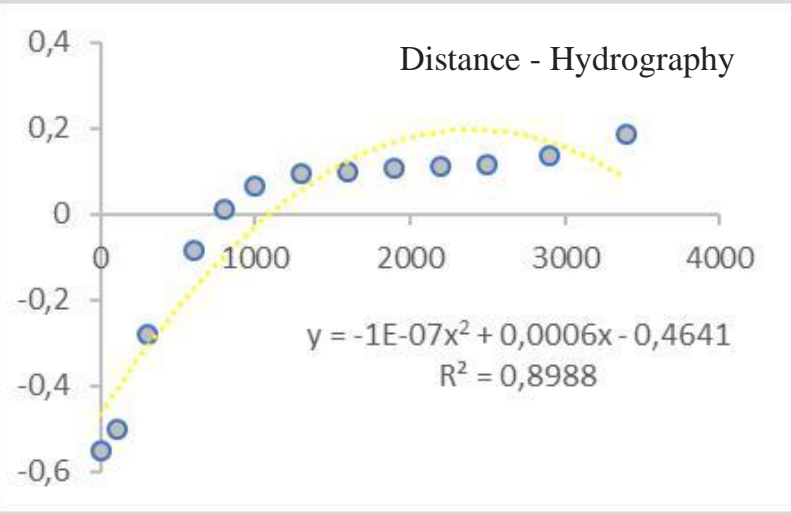

Graph 4: Linear relationship between land use change and hydrographic distances.

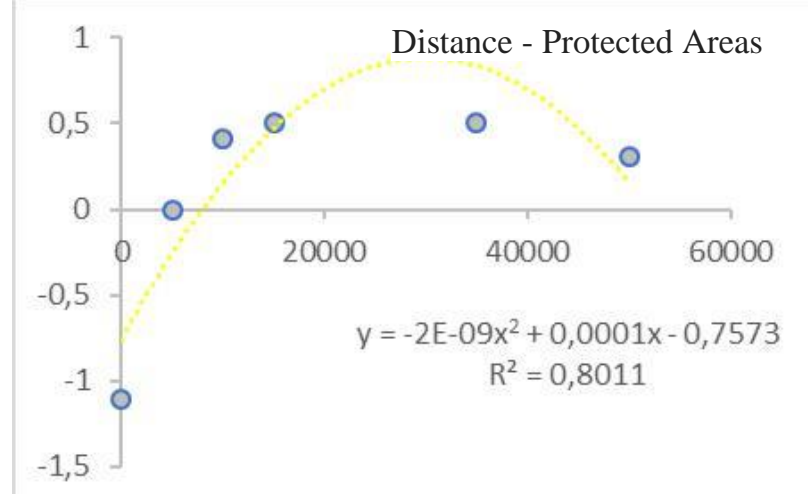

Graphs 5: Linear relationship between land use change and distances from protected areas.

Given the variables that influence land use change, it is noted in the graphs above that the proximity of urban areas, villages and access roads attract deforestation, and the distance of these variables effectively influences land use change. This feature is associated with the economic dynamics of the region, given that the local economy is based on agriculture, so the insertion of access roads and proximity to urban areas is a prime factor to export production and expand new areas, thus triggering the deforestation and landscape transformation in pasture or agriculture areas (Graphs 2 and 3).

In contrast, the distance from hydrography and protected areas such as protected areas and indigenous lands tends to reverse the approach previously addressed. Permanent protected areas Rivercourse Apps and Protected Areas repel deforestation to some extent (Charts 4 and 5), which is described by laws regulating the protection and maintenance of these areas, such as the forest code and delimitation of indigenous lands, etc. Thus, we see the importance of maintaining and creating protected areas 
in order to regulate and minimize the impacts related to the unbridled expansion of agriculture in the region.

The traditional economic logic, in which people deforest to profit from producing agricultural and livestock products, is important, but it is only part of the history of the occupation of lands in the Legal Amazon and the study area, therefore. This relationship represents the process of occupation of the Legal Amazon, in which regions with a larger relative area of forests have little initial deforestation and, as areas are opened by pioneers, new groups of immigrants are encouraged to occupy the territory, increasing deforestation and reducing the relative area of forests. Thus, it remains to be seen whether, once the drivers of change in land cover and land use have been defined, the elaborated model is able to provide the tools for predicting possible future transitional movements of this occupation now observed. For that, we counted on the validation process, which consists in answering if the model faithfully represents the aspects under study associated with a given system.

Validation procedures are used to determine whether the data used in building the model is accurate enough. In addition, they should be sufficient to determine how much of the model is capable of representing reality with sufficient accuracy to be used in prediction and decision making actions.

The construction of the model validation process resulted in the corroboration of the occupation and land use process observed for the study period (Figure 4). From the probability map, we have a projection of the areas that are most likely to transact between natural areas and those occupied by anthropic activities, especially those related to farming activities.
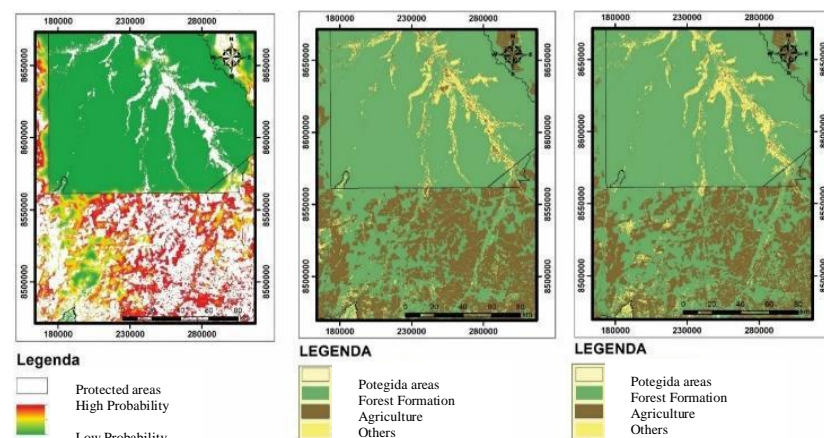

Figure 4: Probability maps, simulated by the model and observed (Map Biome) for the region, for the year 2016. Probability and simulated maps were generated by the validation process and compared with MapBioma.

Protected areas are more effective in reducing deforestation, even in a decreasing scenario of deforestation by the Amazon, due to the various mechanisms already pointed out. The observation is that deforestation has been reduced within these protected areas than in their external areas, pointing to a growing contribution of these areas in reducing deforestation.

In a future scenario (Figure 5), it is noted that the role of protected areas such as protected areas and indigenous lands is given as an important factor in barring or minimizing the process of deforestation and land use change. Despite the pressures from the agribusiness sector and local macroeconomics, in order to serve the foreign market, the importance of maintaining and sustainable use of natural resources should not be ruled out.
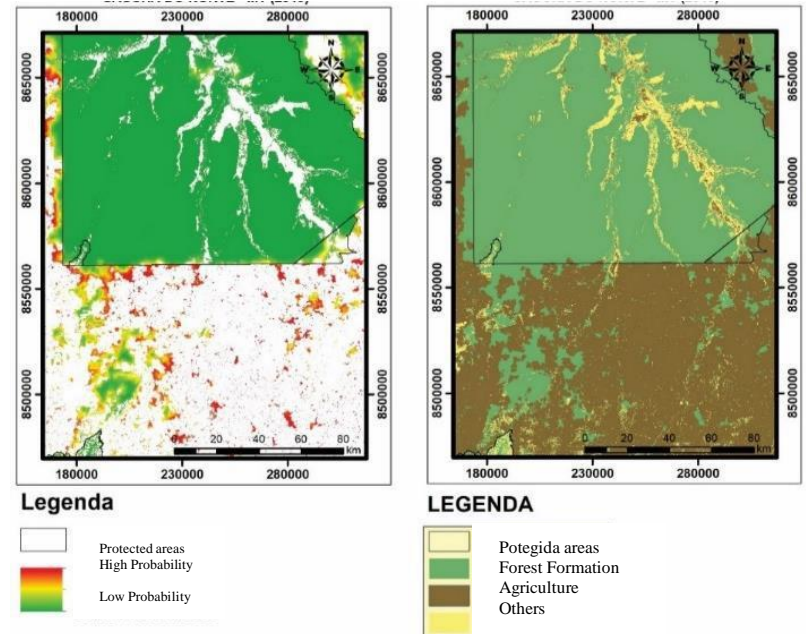

Figure 5: Probability and simulated maps for the year 2040 for the study area.

Since in both maps above, in the 2040 scenario, the forest formation of the region is minimal, except within protected areas, outside these areas almost all forest formation has been transformed into areas for agriculture, and the remaining vegetation has a high probability of transitioning, as shown in the map above.

Graph 6, shows the current situation and a possible future scenario for the year 2030 and 2040, according to the current conditions and characteristics of the place, where the increase of the agricultural sector leads to the reduction of forest areas. Such scenario is worrying due to the importance of the Amazon rainforest, both in its proportion of size, as the configuration in biodiversity and climate regulation.

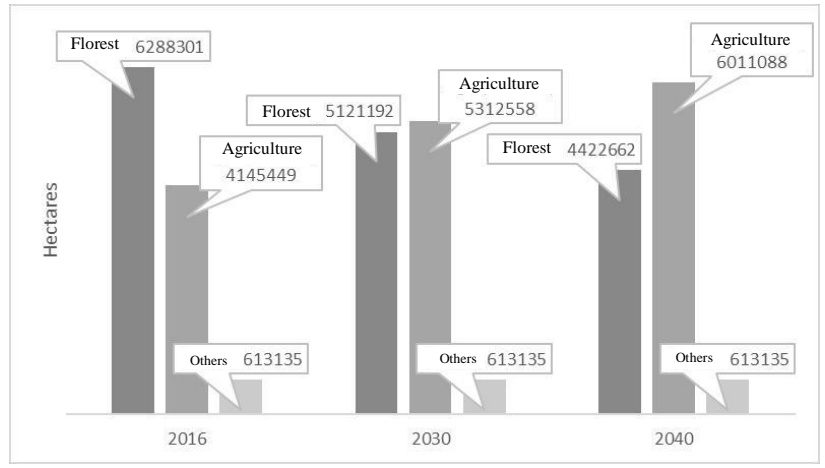

Graph 6: Configuration of current scenario (2016) and simulated scenario of land use change (2030 and 2040) in the region of the municipality of Gaúcha do Norte - MT.

\section{FINAL CONSIDERATIONS}

The uncontrolled advance of land occupation, with the consequent, often irregular, increase in deforestation processes, has produced important and profound changes in space dynamics. Although there has been an increase in recent years in the number of initiatives aimed at controlling the mechanisms of reduction of natural areas, it is noticeable that the advance of agricultural activities, especially those aimed at the foreign market, has led to the reduction of training. leaving them restricted to so-called protected areas.

As a consequence of this process of environmental degradation, there is a growing tendency for the release and concentration of greenhouse gases causing changes in the various natural cycles. 
This will lead to a progressive loss of biodiversity and the possibility of forest survival.

Thus, either by the modeling process or by the technical observation of the LUCC processes, the simulated scenario is not encouraging, when there is a continuity of a tendency for the suppression of forest formations to continue, restricting them only to the areas protected.

\section{REFERENCES}

Agterberg, F.P. and Bonham-Carter, G.F., 1990: Deriving weights of evidence from geoscience contour maps for the prediction of discrete events. XXII Int. Symposium AP-COM, 381-395.

Allen P 1997. Cities and Regions as Self-Organizing Systems: Models of Complexity Amsterdam Gordon Breach Science. Batty M Torrens P Modelling complexity: the limits to prediction. 2001 Centre for Advanced Spatial Analysis, University College London. Working Paper No.36, http://www.casa.ucl.ac.uk/publications/working_papers.htm Batty, M, Xie, Y and Sun, Z. 1999. Modeling urban dynamics through GIS-based cellular automata.. Computers, Environments and Urban Systems, 23: pp. 205-233. Bhttp://doi.org/10.1098/rstb.2012.0153

Bonham-Carter, G., 1994: Geographic information systems for geoscientists: modelling with GIS. Pergamon, 398 pp.

Brando Paulo M., Coe Michael T., DeFries Ruth and Azevedo Andrea A. Ecology, economy and management of an agroindustrial frontier landscape in the southeast Amazon368Phil. Trans. $R$. Soc. Bhttp://doi.org/10.1098/rstb.2012.0152

Goodacre C. M., Bonham-Carter G. F., Agterberg, F. P., Wright D. F., 1993: A statistical analysis of spatial association of seismicity with drainage patterns and magnetic anomalies in western Quebec. Tectonophysics, 217, 205-305.

Kenneth G. Cassman. Ecological intensification of cereal production systems: Yield potential, soil quality, and precision agriculture. Proceedings of the National Academy of Sciences May 1999, 96 (11) 5952-

5959; DOI: 10.1073/pnas.96.11.59.

Macedo Marcia N., Coe Michael T., DeFries Ruth, Uriarte Maria, Brando Paulo M., Neill Christopher and Walker Wayne S. Land-use-driven stream warming in southeastern Amazonia368Phil. Trans. R. Soc.

Morton et al., 2006. D.C. Morton, et al.Cropland expansion changes deforestation dynamics in the southern Brazilian Amazon. Proc. Natl. Acad. Sci. USA, 103 (2006), pp. 1463714641.

Nepstad, D .; Capobianco, J. P .; Barros, A. C .; Carvalho, G .; Moutinho, P .; Lopes, U. And Lefebvre, P. "Advances Brazil, The Environmental Costs for Amazonia”. 2000. http://www.ipam.org.br/avanca/participen.htm.

Organização das Nações Unidas para Alimentação e Agricultura (FAO). Bases de dados estatísticos da FAO ( http://apps.fao.org/) (2012).

Soares-Filho, B. S .; Cerqueira, G. C .; Pennachin, C. L. Dynamics - A stochastic cellular automata model designed to simulate the landsacep dynamics in the Amazonian colonization frotier. Ecological Model, v. 154, p. 2017 - 235. 2002.

Soares-Filho, B.S .; Nepstad, D.C .; Curran, L .; Cerqueira, G.C ; Garcia, R.A .; Ramos, C. A .; Voll, E .; Mcdonald, A .; Lefebvre, P .; Schlesiinger, P .; McGranth, D. ”Deforestation Scenarios for the Amazon". Advanced Studies. 2005.

Tilman D, Cassman Kg, Matson Pa, Naylor R, Polasky S. Agricultural Sustainability And Intensive Production Practices. Nature. 2002 Aug 8;418(6898):671-7. 